\title{
Effects of Preoperative Statin on the Frequency of Ventricular Fibrillation and C-Reactive Protein Level in Patients Undergoing Isolated Coronary Artery Bypass Grafting
}

\author{
Tufan Okumus ${ }^{1}$, Arda Aybars Pala ${ }^{2}$, Temmuz Taner $^{1}$ and Ufuk Aydin ${ }^{3}$ \\ ${ }^{1}$ Department of Cardiovascular Surgery, Mardin State Hospital, Mardin, Turkey \\ ${ }^{2}$ Department of Cardiovascular Surgery, Adiyaman Training and Research Hospital, Adiyaman, Turkey \\ ${ }^{3}$ Department of Cardiovascular Surgery, University of Health Sciences, Bursa Yuksek Ihtisas Training and Research Hospital, Bursa, \\ Turkey
}

\begin{abstract}
Objective: To investigate the effects of statin use in preoperative period on the development of ventricular fibrillation (VF) following the removal of aortic cross-clamp (ACC) and on the levels of inflammation biomarker C-reactive protein (CRP) in patients who undergo elective isolated coronary artery bypass grafting (CABG).

Study Design: Observational study.

Place and Duration of Study: Department of Cardiovascular Surgery, Yuksek Ihtisas Training and Research Hospital, Bursa, Turkey, between May 2019 and January 2020.

Methodology: A total of 104 patients, who underwent elective isolated CABG with cardiopulmonary bypass, were included in this prospective study. Fifty patients, who received statin treatment for at least 16 weeks in preoperative period, were identified as Group S; and 54 patients, who did not receive statin treatment, were identified as Group N. The frequency of VF and defibrillation counter shock (DCS) requirement and postoperative CRP levels were compared in groups after ACC removal.

Results: VF development and related DCS counts were lower at significant levels in Group S compared to Group N ( $p<0.001$ for both). Although no statistically significant differences were detected between the median preoperative CRP levels of the groups; median CRP levels, which were measured in postoperative $2^{\text {nd }}$ and $7^{\text {th }}$ days, were found to be significantly lower in Group $S$ ( $p$ $<0.001$ for both).

Conclusion: Preoperative statin use significantly reduced VF development after the removal of ACC, and decreased postopera-
\end{abstract} tive CRP levels.

Key Words: Coronary artery bypass grafting, Statins, Pleiotropic effect, Ventricular fibrillation, C-reactive protein.

How to cite this article: Okumus T, Pala AA, Taner T, Aydin U. Effects of Preoperative Statin on the Frequency of Ventricular Fibrillation and C-Reactive Protein Level in Patients Undergoing Isolated Coronary Artery Bypass Grafting. J Coll Physicians Surg Pak 2021; 31(04):373-378.

\section{INTRODUCTION}

The most effective option in the treatment of ischemic heart disease is coronary artery bypass grafting (CABG), which is applied to a large number of patients every year. ${ }^{1}$ Despite all the improvements and increased surgical experience in surgical procedures and in cardiac anesthesia; nowadays, CABG-related complications still remain important.

Correspondence to: Dr. Arda Aybars Pala, Department of Cardiovascular Surgery, Adiyaman Training and Research Hospital, Adiyaman, Turkey

E-mail: ardaaybars@hotmail.com

Received: January 16, 2021; Revised: February 14, 2021;

Accepted: March 10, 2021

DOI: https://doi.org/10.29271/jcpsp.2021.04.373
Inflammatory response due to cardiopulmonary bypass (CPB) is blamed in the pathogenesis of many of these complications. Preventing complications and decreasing morbidity and mortality depends not only on perioperative, butalso on preoperative patient management. ${ }^{2}$

Ventricular fibrillation (VF) is a complication associated with $\mathrm{CPB}$; and is very common. Despite effective myocardial protection methods, it may develop after the removal of aortic cross-clamp (ACC). The most important factor in VF development is ischemia-reperfusion damage. The effective treatment is electrical defibrillation counter shock (DCS) application; however, it causes secondary damage to myocardium, and deteriorates the ventricularfunction. ${ }^{3,4}$ For this reason, preventing VF developing after the removal of ACC provides an advantage in maintaining myocardial function following CPB. 
Table I: Comparison of demographic and preoperative data.

\begin{tabular}{|c|c|c|c|}
\hline \multirow{2}{*}{ Variables } & \multirow{2}{*}{$\begin{array}{c}\text { Group N ( } n=54) \\
\text { Mean } \pm \text { S.D/median (IQR)/n (\%) }\end{array}$} & \multirow{2}{*}{$\begin{array}{c}\text { Group S }(\mathbf{n}=50) \\
\text { Mean } \pm \text { S.D/median }(I Q R) / n(\%)\end{array}$} & \multirow{2}{*}{ p-value } \\
\hline & & & \\
\hline Gender (male) & $40(74.1 \%)$ & $42(84 \%)$ & $0.216^{\mathrm{a}}$ \\
\hline Age (years) & $60.9 \pm 7.8$ & $60 \pm 9.2$ & $0.596^{b}$ \\
\hline Height $(\mathrm{cm})$ & $166.2 \pm 8.5$ & $168.7 \pm 6.4$ & $0.086^{b}$ \\
\hline Weight $(\mathrm{kg})$ & $79.9 \pm 11.9$ & $82.2 \pm 12.2$ & $0.331^{b}$ \\
\hline Smoking & $23(42.6 \%)$ & $20(40 \%)$ & $0.789^{a}$ \\
\hline Hypertension & $27(50 \%)$ & $31(62 \%)$ & $0.218^{\mathrm{a}}$ \\
\hline Diabetes mellitus & $20(37 \%)$ & $21(42 \%)$ & $0.605^{\mathrm{a}}$ \\
\hline Peripheral artery disease & $1(1.9 \%)$ & $2(4 \%)$ & $0.607^{d}$ \\
\hline Use of calcium channel blocker & $8(14.8 \%)$ & $5(10 \%)$ & $0.458^{\mathrm{a}}$ \\
\hline Use of ACE inhibitor & $10(18.5 \%)$ & $8(16 \%)$ & $0.734^{\mathrm{a}}$ \\
\hline Use of beta-blocker & $6(11.1 \%)$ & $5(10 \%)$ & $0.854^{\mathrm{a}}$ \\
\hline Left atrium diameter $(\mathrm{mm})$ & $38.3 \pm 4.4$ & $39.3 \pm 3.8$ & $0.197^{b}$ \\
\hline Ejection fraction (\%) & $55.0(47.8-60.0)$ & $55.0(50.0-60.0)$ & $0.724^{c}$ \\
\hline
\end{tabular}

Table II: Comparison of perioperative and postoperative data.

\begin{tabular}{|c|c|c|c|}
\hline \multirow{2}{*}{ Variables } & Group N (n = 54) & Group S $(n=50)$ & \multirow{2}{*}{ p-value } \\
\hline & Mean \pm S.D/median (IQR) & Mean \pm S.D/median (IQR) & \\
\hline CPB time (min) & $86.1 \pm 23.8$ & $96.2 \pm 25$ & $0.036^{b}$ \\
\hline ACC time (min) & $58.1 \pm 18$ & $63.9 \pm 19.6$ & $0.125^{\mathrm{b}}$ \\
\hline Number of grafts used & $3.0(3.0-4.0)$ & $3.0(3.0-4.0)$ & $0.115^{c}$ \\
\hline $\mathrm{pH}$ (measured during $\mathrm{ACC}$ ) & $7.41 \pm 0.09$ & $7.41 \pm 0.08$ & $0.659^{b}$ \\
\hline Potassium (measured during ACC, $\mathrm{mmol} / \mathrm{L}$ ) & $4.05(3.6-4.5)$ & $4.2(3.8-4.9)$ & $0.081^{\mathrm{c}}$ \\
\hline Transvezikal sıcaklık (measured during $\mathrm{ACC},{ }^{\circ} \mathrm{C}$ ) & $32.0(31.0-32.0)$ & $32.0(31.0-32.0)$ & $0.458^{\mathrm{c}}$ \\
\hline VF counts (after ACC removal) & $1.0(0.0-3.0)$ & $0.0(0.0-1.0)$ & $<0.001^{\mathrm{c}}$ \\
\hline DCS counts (after ACC removal) & $1.0(0.0-2.0)$ & $0.0(0.0-1.0)$ & $<0.001^{\mathrm{c}}$ \\
\hline Duration of intensive care unit (day) & $2.0(2.0-3.0)$ & $2.0(2.0-2.3)$ & $0.434^{c}$ \\
\hline Duration of hospitalisation (day) & $7.0(7.0-8.0)$ & $7.0(7.0-8.0)$ & $0.994^{c}$ \\
\hline Preoperative CRP level (mg/dL) & $3.3(3.0-11.2)$ & $4.0(3.0-9.4)$ & $0.783^{c}$ \\
\hline Postoperative $2^{\text {nd }}$ day CRP level (mg/dL) & $174.5(140.3-228.8)$ & $103.5(78.9-125.5)$ & $<0.001^{\mathrm{c}}$ \\
\hline Postoperative $7^{\text {nd }}$ day CRP level (mg/dL) & $83.3(64.7-102.3)$ & $34.1(20.5-64.8)$ & $<0.001^{\mathrm{c}}$ \\
\hline
\end{tabular}

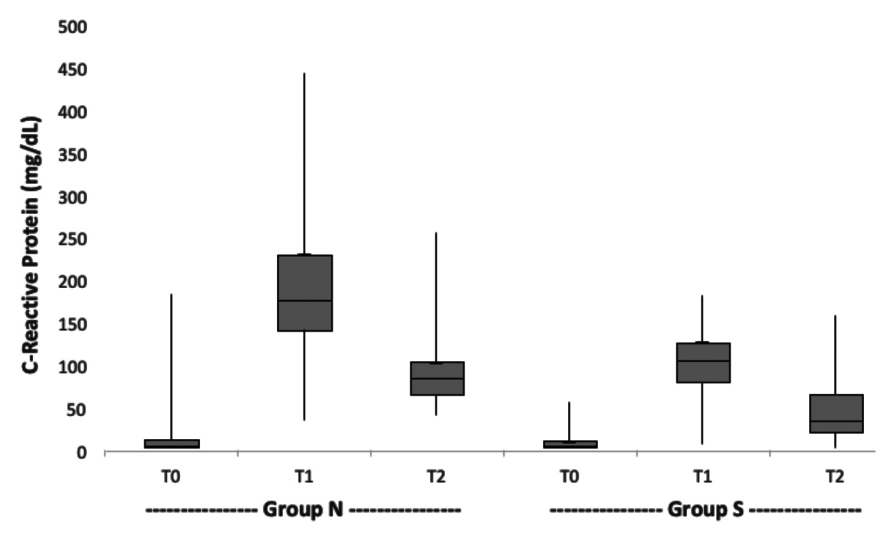

Figure 1: C-reactive protein level change (T0: Preoperative, T1: Postoperative $2^{\text {nd }}$ day, T2: Postoperative $7^{\text {th }}$ day).

Since there is a strong relation between ischemic heart disease and hyperlipidemia, hyperlipidemia treatment is added to the treatment of patients with ischemic heart disease. Statins (3-hydroxy-3-methylglutaryl coenzyme A inhibitors) are used for this purpose. It is already known that statins show pleotropic activity on endothelial functions, inflammation, and coagulation metabolism in addition to their antihyperlipidemic effects. C-reactive protein (CRP) is an inflammation biomarker. Statins cause a decrease indirectly in CRP levels with their anti-inflammatory effects. ${ }^{5,6}$ Statins reduce complications related to CPB in cardiac surgery with their anti-inflammatory, antioxidant, and indirect antiarrhythmic effects. ${ }^{2}$

The purpose of the present study was to compare the frequency of VF developing after ACC removal and DCS requirements, and CRP levels, which is an inflammation biomarker, in patients who underwent elective isolated CABG, with and without statin use in the preoperative period.

\section{METHODOLOGY}

A total of 104 patients, who underwent elective isolated CABG with CPB between May 2019 and January 2020 in 
Cardiovascular Surgery Clinic, University of Health Sciences, Bursa Yuksek Ihtisas Training and Research Hospital, Bursa, Turkey, were included in this prospective study. Local Ethics Committee approval was received. (Approval No. 2011KAEK-25 2019/04-15). The patients were divided into two groups. A total of 50 patients, who had been receiving statin treatment for at least 16 weeks at the time of admission to the clinic, were identified as Group S; and 54 patients, who did not use any antihyperlipidemic agents, were identified as Group N. Patient who underwent emergency surgical intervention, reoperation, patients with under $40 \%$ ejection fraction, additional cardiac disease requiring surgical intervention, arrhythmia other than sinus rhythm, antiarrhythmic treatment, chronic renal or hepatic disease, inflammatory disease requiring anti-inflammatory treatment, electrolyte imbalance, mortality in the first 7 days, and those intubated for more than 24 hours in postoperative period, were excluded from the study.

Patients in Group S used one of the atorvastatin, rosuvastatin, pravastatin, simvastatin or fluvastatin group statins as antihyperlipidemic drugs. The statin treatments of these patients were stopped on the day of the operation, and was started again on the first postoperative day. The demographic data, comorbidities, and perioperative and postoperative data of all patients were recorded. Routine 12-lead electrocardiography (ECG) results were recorded in preoperative period. CRP levels were recorded from the blood samples taken with antecubital vein at the time of admission to our clinic, and on postoperative $2^{\text {nd }}$ and $7^{\text {th }}$ days.

Midazolam $0.003 \mathrm{mg} / \mathrm{Kg}$, fentanyl $5 \mathrm{pg} / \mathrm{Kg}$, and vecuronium bromide $0.1 \mathrm{mg} / \mathrm{kg}$ IV were applied in anesthesia induction; and $5 \mathrm{pg} / \mathrm{Kg}$ fentanyl and $0.5-1 \mathrm{mg} / \mathrm{Kg}$ vecuronium bromide were applied for the maintenance dose. Standard median sternotomy was performed and left internal thoracic artery and saphenous vein grafts were prepared. CPB was entered with venous cannulation with two-stage cannulation from the right atrium and with arterial cannulation from the ascending aorta. Cold crystalloid cardioplegia was given from the anterograde route to protect the myocardium after ACC, and cold blood cardioplegia was given after each anastomosis or every 15 minutes for maintenance. Hot blood cardioplegia was given to avoid reperfusion damage before the ACC was removed. Right after ACC was removed, 100 mg lidocaine was administered. Moderate hypothermia $\left(28^{\circ} \mathrm{C}-32^{\circ} \mathrm{C}\right)$ was applied in $\mathrm{CPB}$, and roller pump and membrane oxygenator were used. The pump flow was set between 2.2-2.4 $\mathrm{lt} / \mathrm{min} / \mathrm{m}^{2}$ to obtain an average arterial pressure of $50-60 \mathrm{mmHg}$ during ACC. Hematocratic levels were kept between $20-25 \%$. Heating was performed until the bladder temperature reached $36^{\circ} \mathrm{C}$ after $\mathrm{ACC}$, and $\mathrm{CPB}$ was terminated after proper blood pressure and cardiovascular stability were achieved. In postoperative period of the patients, continuous ECG and arterial pressure monitoring was carried out with standard D II derivation in intensive care unit. Patients who had normal clinical progression were transferred to the unit bed after the removal of the drainage on the second day of postoperative.

Statistical analyses were done with SPSS 21 (IBM SPSS Statistic Inc. version 21.0, Chicago, IL, USA). Continuous variables were expressed as mean \pm standard deviation, median ( $25^{\text {th }}$ percentile- $75^{\text {th }}$ percentile) and nominal variables were expressed as frequency and percentage. The Chisquare test or Fisher's Exact test were used to compare two independent groups for nominal variables. The Kolmogorov-Smirnov normality test was used to determine the distribution of continuous variables. The Student's t-test was used to compare two independent groups for continuous variables that fit normal distribution. The Mann-Whitney U-test was used to compare two independent groups for continuous variables that did not fit normal distribution. Tests of significant differences between different CRP levels measured at each time point and at different time points were performed using the Friedman test and the Wilcoxon Signed-Rank tests. A p $<0.05$ was considered to be statistically significant in all tests.

\section{RESULTS}

A total of 104 patients were included in the present study. There were 54 patients $(74.1 \%$ males, mean age: $60.9 \pm 7.8$ years) in Group N; and there were 50 patients ( $84 \%$ males, mean age: $60 \pm 9.2$ years) in Group $\mathrm{S}$. The demographic characteristics and preoperative data of the patients are presented in Table I. No significant differences were detected between the patient groups in terms of age, gender, height, weight, smoking status, hypertension, diabetes mellitus, peripheral artery disease, calcium channel blocker use, angiotensin converting enzyme inhibitor use, beta blocker use, left atrium diameter and ejection fraction.

Among the evaluated perioperative variables, ACC duration, number of grafts used, $\mathrm{pH}$ and potassium values in blood gas were evaluated during ACC, and transvesical temperature measurement were not significantly different among patient groups. VF development after ACC removal, and related DCS counts were significantly higher in Group N (both $p<0.001$ ). In Group S, lower mean CPB time due to faster sinus rhythm and faster cardiac stability due to less VF development and less need for DCS after ACC removal were expected; but contrary to expectations, it was found to be significantly higher ( $p=0.036$, Table II).

When preoperative CRP levels were evaluated, although patients in Group S had lower median values, these differences were not statistically significant. It was found that the median CRP levels measured on postoperative $2^{\text {nd }}$ and $7^{\text {th }}$ days were significantly lower in Group $S$ ( $p<0.001$ and $p$ $<0.001$ ) (Table II, Figure 1). It was also seen that VF development, DCS need, and postoperative CRP levels were low in Group S, and this did not have a significant effect on the duration of intensive care unit and hospitalization (Table II). 
When CRP levels of patients measured in preoperative period were called T0, those measured on postoperative $2^{\text {nd }}$ day were called $T 1$, and those measured on postoperative $7^{\text {th }}$ day were called T2; statistically significant difference was found in Group N in the overall effect of time on CRP levels $(p<0.001)$. Similarly, statistically significant difference was found in Group $S(p<0.001)$. In addition, the increase in CRP levels in the T1-T0 and T2-T0 periods and the decrease in the CRP levels in the T2-T1 periods were found to be statistically significant in both groups (all $p<0.001$, respectively).

\section{DISCUSSION}

In the present study, the effects of statin use in the preoperative period in patients with isolated CABG on VF frequency after ACC removal, DCS need, and levels of CRP, which is an inflammation marker, were investigated. In the patient group using statins in preoperative period, VF development following the removal of ACC and related DCS counts were significantly lower. The fact that statins decrease the frequency of VF, which is thought to be caused by ischemia-reperfusion injury after ACC removal, suggests that it is due to their anti-inflammatory effects. In this study, the fact that postoperative CRP levels were significantly lower in the group of patients who used statins in the preoperative period, supports this. With this study, to the best of authors' knowledge, it was determined for the first time in the literature that preoperative statin use reduces the frequency of VF developing after the removal of ACC, and postoperative CRP levels.

VF is a complication increasing the CPB-related morbidity and mortality. Specially, the VF incidence after the removal of ACC was reported to be $45-90 \%$, although it depended on surgical procedure, cardioplegia solution and technique applied. ${ }^{7}$ Myocardial ischemia, reperfusion damage, inflammatory response, and electrical instability are blamed in its pathophysiology. The most effective treatment for VF after ACC removal is DCS. However, although cardiac arrhythmia is corrected with DCSs, it is known that secondary damage occurs to the myocardium. ${ }^{8}$ This situation has created a need for prophylactic treatment.

Statins have pleiotropic effects besides their cholesterol reducing effects, which are their main use. Pleiotropic effects of statins are anti-inflammatory effects, such as improving endothelial functions, reducing proliferation in vascular smooth muscle cells, increasing atherosclerotic plaque stability, antioxidant effects, preventing platelet activation, and decreasing proinflammatory cytokines through monocytes and macrophages. ${ }^{9,10}$ Among the pleiotropic effects, the most important one is mentioned as anti-inflammatory effects in many studies. Diamantis et al. reported that statins provide improvements in coronary artery disease prognosis with its anti-inflammatory effects on endothelial cells and on atherosclerotic plaques. ${ }^{11}$ In the review, which was published by Soulaidopoulos et al., it was reported that the useful effects of statins on cardiovascular risks that are associated with rheumatoid arthritis, which is an inflammatory disease appear with their anti-inflammatory effects. ${ }^{12}$ It was reported that statin treatment should be used for an average period of 14-16 weeks to improve endothelial functions and to reduce serum inflammatory markers. ${ }^{13,14}$ For this reason, we included those patients who had received statin treatment for at least 16 weeks at the time of admission to this clinic in to the patient group using statins; and consequently, low postoperative CRP levels in patient group using statins were indicative of treatment efficacy.

An inflammatory response occurs due to CPB in cardiac surgery. The earlier the patient is protected against this inflammatory response, which is given by the body as a natural self-defense mechanism, the less the patient is affected by the complications that might develop after the operation. Proinflammatory and inflammatory mediators have been investigated in this regard, and specially the increase in CRP levels, which is a primitive inflammatory acute phase protein, is an important marker in inflammatory response. ${ }^{15}$ In cardiovascular diseases, anti-inflammatory treatments improve the prognosis of the disease and reduce the development of complications, and studies have been conducted on the use of statin for this purpose. It was seen in a randomised controlled trial that was conducted by Ridker et al. with 17,802 apparently healthy people without hyperlipidemia and with high CRP levels, that there was 37\% decrease in CRP levels and a significant decrease in major cardiovascular event incidence in the group of patients receiving statins. ${ }^{16}$ In their observational study that included 126 non-ST-segment elevation acute coronary syndrome patients, Jiao et al. reported that statin (rosuvastatin) treatment alleviated the increase in CRP levels due to percutaneous coronary intervention, and also reduced myocardial damage. ${ }^{17}$ In the present study, it was seen that there were lower CRP levels at significant levels in the postoperative period in the group of patients who used statin in preoperative period compared to the group that did not use it (postoperative $2^{\text {nd }}$ day (median): $103.5 \mathrm{mg} / \mathrm{dL}$ vs. $174.5 \mathrm{mg} / \mathrm{dL}, \mathrm{p}$ $<0.001$; postoperative $7^{\text {th }}$ day (median): $34.1 \mathrm{mg} / \mathrm{dL}$ vs. 83.3 $\mathrm{mg} / \mathrm{dL}, \mathrm{p}<0.001$ ).

In addition to the anti-inflammatory effects of statins, they are known to improve cardiovascular autonomic balance and thus reduce arrhythmia tendency. ${ }^{18}$ In a systematic review that was published by Bazoukis et al., it was reported that statins decreased the frequency of ventricular arrhythmia with antiarrhythmic effect in heart failure patients with implantable cardioverter defibrillator. ${ }^{19}$ In the review published by Oesterle et al., the antiarrhythmic effects of statins and their positive effects on the development of atrial fibrillation and ventricular tachyarrhythmias in cardiovascular diseases were emphasised. ${ }^{20}$

There are more studies in the literature on the preventive effects of statins on the development of atrial fibrillation in 
cardiac surgery, rather than ventricular arrhythmias. Aydin et al., in their prospective randomised controlled study, reported that the use of statins in the early postoperative period in CABG patients reduced the risk of postoperative atrial fibrillation by $49 \% .^{21}$ In a meta-analysis of 12 studies $(8,458$ patients), published by Zheng et al, it was reported that preoperative statin therapy reduced the incidence of postoperative atrial fibrillation. ${ }^{22}$ Unlike these studies, in this study, in which VF development after ACC removal was evaluated, the median values of VF and DCS counts that developed after ACC removal in patients who used statins in preoperative period, were significantly lower than in patients who did not use statins (both $<0.01$ vs. 1.0, p $<0.001$, respectively). According to these results, it is indirectly seen that preoperative statin treatment reduces myocardial injury due to CPB with anti-inflammatory and antiarrhythmic effects.

Nowadays, antiarrhythmic such as amiodarone and lidocaine are used to prevent the development of VF after ACC removal in the perioperative period. Samantaray et al. conducted a randomised controlled prospective study and reported that VF developed at lower rates in the patient group they administered $150 \mathrm{mg}$ amiodarone before the ACC was removed when compared with the control group without extra medication ( $18 \%$ vs. $65 \%, p=0.01){ }^{23}$ In their prospective study that included 34 CABG patients, Baraka et al. reported that $11 \%$ developed VF in the group of patients they administered $100 \mathrm{mg}$ lidocaine before ACC was removed, and $70 \%$ in the control group ( $p<0.0005)$; and they observed higher cardiac output after leaving CPB in the group to which lidocaine was administered, and this was associated with a decrease in DCS requirement. ${ }^{3}$ In this clinic, as a routine practice, lidocaine is administering to patients right after ACC removal; and in order not to affect the results of this study, equal doses of lidocaine were administered in both of these study groups without upsetting the routine practice.

This study had some limitations. Firstly, it had a single-centred design, and relatively low patient number. Secondly, only CRP was evaluated as an inflammation marker in this study in which the anti-inflammatory properties of statins were emphasised. Thus, more comprehensive studies should be planned with other inflammation markers. Thirdly, the use of different statin group drugs in the perioperative period. Fourthly, the effects of statin group drugs on the complications after CABG were reported to be dose-dependent. $^{24}$

In this study, however, only the lower limit was determined in the usage period of statin treatment for standardisation purposes in patient selection; and the LDL cholesterol levels, with which the effectiveness of the treatment could be evaluated, were not considered. For this reason, studies should be planned on which effective dose should be used to ensure prophylaxis reliability of complications with statin group drug usage in preoperative period in CABG patients.

\section{CONCLUSION}

The use of statins during preoperative period in patients with isolated $C A B G$ resulted in significant decreases in VF frequency after the removal of ACC, and postoperative CRP levels. The authors believe that applying routine statin treatment is useful in preoperative period in patients who undergo elective isolated CABG.

\section{ETHICAL APPROVAL:}

The study was approved by University of Health Sciences, Bursa Yuksek Ihtisas Training and Research Hospital, Clinical Research Ethics Committee. (Approval No. 2011-KAEK-25 2019/04-15).

\section{CONFLICT OF INTEREST:}

Authors declared no conflict of interest.

\section{PATIENTS' CONSENT:}

All patients signed a document of informed consent.

\section{AUTHORS' CONTRIBUTION:}

TO, AAP: Conception or design of the work, or the acquistion, analysis, or interpretation of data for the work, drafting the work or revising it critically for important intellectual content.

TT: Acquistion, analysis, or interpretation of data for the work, drafting the work or revising it critically for important intellectual content.

UA: Acquistion, analysis, or interpretation of data for the work, drafting the work or revising it critically for important intellectual content and final approval of the version to be published.

\section{REFERENCES}

1. Pala AA, Taner T, Tatli AB, Ozsin KK, Yavuz S. The effect of preoperative hematocrit level on early outcomes after coronary artery bypass surgery. Cureus 2020; 12(4): e7811. doi: 10.7759/cureus.7811.

2. Siskos D, Tziomalos K. The role of statins in the management of patients undergoing coronary artery bypass grafting. Diseases 2018; 6(4):102. doi: 10.3390/diseases6040102.

3. Baraka A, Kawkabani N, Dabbous A, Nawfal M. Lidocaine for prevention of reperfusion ventricular fibrillation after release of aortic cross-clamping. J Cardiothorac Vasc Anesth 2000; 14(5):531-533. doi: 10.1053/jcan.2000. 9484.

4. Cheng N, Gao C, Wang R, Yang M, Zhang L. New-onset ventricular arrhythmias in patients with left ventricular dysfunction after coronary surgery: Incidence, risk factors, and prognosis. Heart Surg Forum 2018; 21(2):E117-E123. doi: 10.1532/hsf.1944.

5. Nissen SE, Tuzcu EM, Schoenhagen P, Crowe T, Sasiela WJ, 
Tsai J, et al. Statin therapy, LDL cholesterol, C-reactive protein, and coronary artery disease. N Engl J Med 2005; 352(1):29-38. doi: 10.1056/NEJMoa042000.

6. Athyros VG, Kakafika Al, Tziomalos K, Karagiannis A, Mikhailidis DP. Pleiotropic effects of statins--clinical evidence. Curr Pharm Des 2009; 15(5):479-89. doi: 10.2174/ 138161209 787315729.

7. Zheng Y, Gu Q, Chen HW, Peng HM, Jia DY, Zhou Y, et al. Efficacy of amiodarone and lidocaine for preventing ventricular fibrillation after aortic cross-clamp release in open heart surgery: a meta-analysis of randomised controlled trials. J Zhejiang Univ Sci B 2017; 18(12): 1113-22. doi: 10.1631/jzus.B1700229.

8. Mita N, Kagaya S, Miyoshi S, Kuroda M. Prophylactic effect of amiodarone Infusion on reperfusion ventricular fibrillation after release of aortic cross-clamp in patients with left ventricular hypertrophy undergoing aortic valve replacement: A randomised controlled trial. J Cardiothorac Vasc Anesth 2019; 33(5):1205-13. doi: 10.1053/j.jvca. 2018.10. 005.

9. Takemoto M, Liao JK. Pleiotropic effects of 3-hydroxy-3-methylglutaryl coenzyme a reductase inhibitors. Arterioscler Thromb Vasc Biol 2001 Nov; 21(11):1712-9. doi: 10.1161/hq1101.098486.

10. Oesterle A, Laufs U, Liao JK. Pleiotropic effects of statins on the cardiovascular system. Circ Res 2017; 120(1):229-43. doi: 10.1161/CIRCRESAHA.116.308537.

11. Diamantis E, Kyriakos G, Quiles-Sanchez LV, Farmaki P, Troupis T. The anti-ınflammatory effects of statins on coronary artery disease: An updated review of the literature. Curr Cardiol Rev 2017; 13(3):209-16. doi: 10.2174/1573 $403 \times 13666170426104611$.

12. Soulaidopoulos S, Nikiphorou E, Dimitroulas T, Kitas GD. The Role of Statins in Disease Modification and Cardio-vascular Risk in Rheumatoid Arthritis. Front Med (Lausanne) 2018; 5:24. doi: 10.3389/fmed.2018.00024.

13. Kinlay S, Schwartz GG, Olsson AG, Rifai N, Leslie SJ, Sasiela WJ, et al. High-dose atorvastatin enhances the decline in inflammatory markers in patients with acute coronary syndromes in the MIRACL study. Circulation 2003; 108(13):1560-6. doi: 10.1161/01.CIR.0000091404.095 58.AF.

14. Node K, Fujita M, Kitakaze M, Hori M, Liao JK. Short-term statin therapy improves cardiac function and symptoms in patients with idiopathic dilated cardiomyopathy. Circulation 2003; 108(7):839-43. doi: 10.1161/01. CIR.0000084539. 58092.DE.

15. Giacinto O, Satriano U, Nenna A, Spadaccio C, Lusini M, Mastroianni $C$, et al. Inflammatory response and endothelial dysfunction following cardiopulmonary bypass: patho- physiology and pharmacological targets. Recent Pat Inflamm Allergy Drug Discov 2019; 13(2):158-73. doi: 10.2174/1872213X13666190724112644.

16. Ridker PM, Danielson E, Fonseca FA, Genest J, Gotto AM Jr, Kastelein JJ, et al. Rosuvastatin to prevent vascular events in men and women with elevated C-reactive protein. $N$ Engl J Med 2008; 359(21):2195-2207. doi: 10.1056/ NEJMoa 0807646.

17. Jiao Y, Hu F, Zhang Z, Gong K, Sun X, Li A, et al. Efficacy and safety of loading-dose rosuvastatin therapy in elderly patients with acute coronary syndromes undergoing elective percutaneous coronary intervention. Clin Drug Investig 2015; 35(12):777-84. doi: 10.1007/s40261- 015-0335-1.

18. Welzig CM, Shin DG, Park HJ, Kim YJ, Saul JP, Galper JB. Lipid lowering by pravastatin increases parasympathetic modulation of heart rate: Galpha (i2), a possible molecular marker for parasympathetic responsiveness. Circulation 2003; 108(22):2743-6. doi: 10.1161/01.CIR.00001 03680. 61390.16.

19. Bazoukis G, Papadatos SS, Letsas KP, Pagkalidou E, Korantzopoulos P. Impact of statin therapy on all-cause mortality and ICD interventions in heart failure patients - a systematic review. Acta Cardiol 2017; 72(5):547-52. doi: 10.1080/00015385.2017.1310562.

20. Oesterle A, Liao JK. The pleiotropic effects of statins - from coronary artery disease and stroke to atrial fibrillation and ventricular tachyarrhythmia. Curr Vasc Pharmacol 2019; 17(3):222-32. doi: 10.2174/15701611166661808171 55058.

21. Aydın U, Yılmaz M, Düzyol Ç, Ata Y, Türk T, Orhan AL, et al. Efficiency of postoperative statin treatment for preventing new-onset postoperative atrial fibrillation in patients undergoing isolated coronary artery bypass grafting: A prospective randomised study. Anatol J Cardiol 2015; 15(6):491-5. doi: 10.5152/akd.2014.5531

22. Zheng H, Xue S, Hu ZL, Shan JG, Yang WG. The use of statins to prevent postoperative atrial fibrillation after coronary artery bypass grafting: A meta-analysis of 12 studies. J Cardiovasc Pharmacol 2014; 64(3):285-92. doi: 10.1097/FJC.0000000000000102.

23. Samantaray A, Chandra A, Panigrahi S. Amiodarone for the prevention of reperfusion ventricular fibrillation. J Cardiothorac Vasc Anesth 2010; 24(2):239-43. doi: 10.1053/j.jvca.2009.07.007.

24. Ouattara A, Benhaoua H, Le Manach Y, Mabrouk-Zerguini N, Itani O, Osman A, et al. Perioperative statin therapy is associated with a significant and dose-dependent reduction of adverse cardiovascular outcomes after coronary artery bypass graft surgery. J Cardiothorac Vasc Anesth 2009; 23(5):633-8. doi: 10.1053/j.jvca. 2009.02. 008. 